\title{
A Survey of the SWISS Researchers on the Impact of Sibling Privacy Protections on Pedigree Recruitment
}

\author{
Bradford B. Worrall ${ }^{a, b}$ Donna T. Chen ${ }^{b, c, d}$ Robert D. Brown, Jr.e \\ Thomas G. Brott $^{f}$ James F. Meschia ${ }^{f}$ for the SWISS investigators ${ }^{1}$ \\ Departments of ${ }^{a}$ Neurology, ${ }^{b}$ Health Evaluation Sciences, ${ }^{c}$ Psychiatric Medicine and ${ }^{\mathrm{d}}$ Center for Biomedical \\ Ethics, University of Virginia, Charlottesville, Va., e Department of Neurology, Mayo Clinic, Rochester, Minn., \\ and ${ }^{\mathrm{f}}$ Department of Neurology, Mayo Clinic, Jacksonville, Fla., USA
}

\section{Key Words}

Ethics $\cdot$ Genetic research $\cdot$ Pedigree $\cdot$ Stroke

\begin{abstract}
To understand the perceptions and attitudes about privacy safeguards in research and investigate the impact of letter-based proband-initiated contact on recruitment, we surveyed researchers in the Siblings With Ischemic Stroke Study (SWISS). All 49 actively recruiting sites provided at least 1 response, and $61 \%$ reported that potential probands were enthusiastic. Although $66 \%$ of researchers valued proband-initiated contact, only $23 \%$ said that probands viewed this strategy as important to protecting the privacy of siblings. A substantial minority of researchers $(37 \%)$ said the strategy impeded enrollment, and $44 \%$ said it was overly burdensome to probands.
\end{abstract}

Copyright $(2005$ S. Karger AG, Basel

1 For names of investigators, see Appendix 1.

\section{KARGER}

(c) 2005 S. Karger AG, Basel

Fax +4161306 1234

E-Mail karger@karger.ch

www.karger.com

\section{Introduction}

Pedigree-based research is an important tool for investigating the genetics of complex disorders such as ischemic stroke. In pedigree-based designs, data and DNA samples collected from probands are useful to researchers only if targeted relatives also participate. At the same time, use of pedigree-based research requires strategies to enhance the privacy protection of family members who may or may not become research subjects [1-5]. In response to both scientific and ethical pressures, research procedures change rapidly and create a need for ongoing assessment of such strategies. Research team members play a crucial role in maintaining ethical standards in research [6]. As with many procedures designed to enhance the ethics of research, strategies developed to enhance privacy protection are more likely to succeed when members of the research team recognize their importance as outweighing the added burden incurred [7].

The Siblings With Ischemic Stroke Study (SWISS) is a large-scale multisite study sponsored by the National Institutes of Health that was specifically designed to investigate the genetic risk for ischemic stroke [8]. SWISS uses a genome-wide screen to identify novel genetic risk
Dr. James F. Meschia

Department of Neurology, Mayo Clinic

4500 San Pablo Road

Jacksonville, FL 32224 (USA)

E-Mail meschia.james@mayo.edu 
factors through linkage analysis in pairs of siblings who are concordant or discordant for ischemic stroke. It has a target enrollment of 800 participants from 300 families. The study relies on rigorous phenotyping using a standardized reliable classification system for stroke subtyping [9]. Because of the projected number of enrolled concordant sibling pairs, the study has approximately $70 \%$ power to detect linkage between a marker and a moderately strong susceptibility locus; the power to detect linkage is increased by the inclusion of discordant siblings [8].

Investigators recruit siblings using letter-based proband-initiated contact, a strategy chosen to minimize intrusion on siblings and to enhance the privacy of siblings during the recruitment phase $[5,10]$. Potential probands with ischemic stroke are identified by treating physicians, told about SWISS, and referred if interested. A local SWISS research team member approaches the potential proband to determine if the proband has any living siblings with a history of ischemic stroke but does not obtain personal identifiers on any relative. Probands with at least 1 sibling concordant for ischemic stroke provide informed consent to personally participate in the protocol and to contact siblings about the study. Each proband is given a postage-paid letter of invitation to sign, add a personal note to if desired, and send to each living sibling. The letter introduces SWISS as a study looking for a genetic component to stroke risk in siblings with or without a history of stroke and includes a postage-paid reply card for the sibling to return to the central Clinical Coordinating Center (CCC) to indicate whether a SWISS researcher may call to discuss the study further and to provide contact information. If siblings decline further contact, they may indicate so on the reply card without giving any identifying information. If no concordant sibling reply is received within 4 weeks, the local researcher is prompted to recontact the proband to verify that letters were sent or to offer another set of letters for all siblings. CCC personnel contact interested siblings after receipt of reply cards, explain the details of the study, screen for eligibility, and conduct the informed consent process. In this strategy, researchers do not contact siblings without their prior written permission. DNA from probands is collected only if a verified concordant sibling agrees to participate. An additional discordant sibling may also be enrolled.

When this letter-based proband-initiated contact was adopted for sibling recruitment, members of the SWISS Executive Committee voiced concern that it might substantially burden recruitment efforts and negatively affect the experience for researchers and probands. Letter- based proband-initiated contact was instituted with the understanding that its impact would be evaluated during the trial. As part of this evaluation, we surveyed investigators and coordinators participating in SWISS about their perceptions and experiences with this method of recruitment.

\section{Methods}

\section{Research Population}

All 49 active SWISS sites were surveyed [United States ( $n=46$; 26 states) and Canada ( $\mathrm{n}=3 ; 2$ provinces)]. Principal investigators (PIs) and coordinators for each site were invited to respond; PIs and named coordinators were also encouraged to invite additional coordinators and subinvestigators to respond. Proband enrollment for the overall study and for individual sites was recorded from a separate data source for comparisons with the survey results. These data were not linked to the survey responses because of confidentiality protections promised to survey respondents.

\section{Development of the Questionnaire}

We created a single-page questionnaire exploring 4 domains: (1) researchers' perceptions of proband attitudes toward SWISS and proband-initiated contact; (2) researchers' attitudes toward proband-initiated contact and its impact on recruitment; (3) the recruitment experience at the sites, and (4) experiences with local research ethics committee review. Attitudinal questions were answered on a 5-point Likert scale. Experiential questions were multiple-choice or 'Yes/No'. Site volume in terms of numbers of probands approached was used as a proxy for site experience with recruitment for SWISS. Opportunities were also offered for free-text responses. The original draft of the questionnaire was circulated among members of the SWISS operations committee for content and to non-SWISS research staff for readability and clarity. The final questionnaire was sent both to investigators and to coordinators (appendix 2). All respondents were asked to answer the attitudinal questions. The questionnaire asks that the coordinator from each site give the experiential data with instructions to consult the PI as needed.

\section{Recruitment}

The survey was conducted during a 12-week period (between November 2002 and January 2003). All named PIs and coordinators were sent an invitation by e-mail, along with an electronic copy of the questionnaire, which was assigned a tracking number. Surveyed persons were told that preliminary survey results would be presented in terms of anonymous group summary statistics at the annual meeting of the SWISS investigators in February 2003. Persons who were unreachable by e-mail were contacted by fax or through other research staff at their site. Four weeks after the initial e-mail message was sent, a follow-up global e-mail was sent from the PI for the overall study (J.F.M.). Subsequent reminders were targeted at nonrespondents. Six and 10 weeks after the initial e-mail message was sent, individual faxes were sent to all nonrespondents. During the 12 th week, a final telephone appeal was made to the few sites with no response from either the coordinator or the PI. To render the data anonymous, no identifying information was col- 
lected and tracking codes were stripped after all responses were obtained. The University of Virginia Human Investigations Committee granted this survey exempt status.

\section{Adjudication of Conflicting Responses}

Data on coordinator and investigator attitudes are presented for all respondents. Although the survey was designed to obtain only 1 set of experiential data from each site, we anticipated duplicate and conflicting responses from multiple respondents at the same site. While recording all the data, we prioritized coordinator responses and used PI responses only when no coordinator response was received. When multiple coordinators responded, we used data from the questionnaire with the most complete response for this section.

\section{Statistical Methods}

Baseline characteristics and data on research experiences are reported as percentages. To allow comparisons, Likert responses were dichotomized into 'favorable' or 'not favorable' or into 'unfavorable' or 'not unfavorable'. Neutral responses were reported separately in situations in which the neutral responses accounted for more than one third of the responses. Responses for all the coordinators were categorized together. The responses of the PIs and subinvestigators were also categorized together. Differences between the responses of coordinators and investigators were tested using the Pearson $\chi^{2}$ statistic. Exploratory analyses examined the impact of prior personal experience with genetic research and the site volume of potential probands approached on researcher attitudes and perceptions. Alpha was set at 0.05 .

\section{Results}

At least 1 response was received from each site $(\mathrm{n}=$ 49 ; site response rate $=100 \%$ ). At 1 site, the PI also functioned as the coordinator. At least 1 coordinator responded from each of the 48 sites with a separate research coordinator (coordinator response rate $=100 \%$ ). We received responses from 8 other coordinators at 6 different sites (range, 1-3 coordinator responses per site). A total of 45 of 49 PIs responded (92\%). Nine additional subinvestigators from 9 sites responded. Overall, the coordinators and PIs are experienced in stroke prevention and treatment research (table 1). Experience with genetics trials was less extensive for both groups: only $35 \%$ of coordinators and $36 \%$ of investigators reported prior experience with any genetic research.

\section{Experience with Recruiting Siblings for SWISS}

The sites reported a wide range of experience with recruitment. The first site was initiated in October 2000. The newest site joined in August 2002. When the survey began in November 2002, 26 months after initiation of the first site, 320 probands had been provided with letters to mail to their siblings. From 320 probands enrolled, 86
Table 1. Prior research experience

\begin{tabular}{lrrrrr}
\hline Clinical trial experience & \multicolumn{2}{l}{$\begin{array}{l}\text { Investigators } \\
(\mathrm{n}=54)\end{array}$} & & \multicolumn{2}{l}{$\begin{array}{l}\text { Coordinators } \\
(\mathrm{n}=57)\end{array}$} \\
\cline { 2 - 3 } & $\mathrm{n}$ & $\%$ & & $\mathrm{n}$ & $\%$ \\
\hline Any stroke treatment & 54 & 100 & & 47 & 82 \\
$\quad$ Stroke therapeutics & 52 & 96 & & 45 & 79 \\
Stroke prevention & 54 & 100 & & 41 & 72 \\
Any genetics & 20 & 37 & & 20 & 35 \\
Stroke genetics & 17 & 31 & & 16 & 28 \\
Nonstroke genetics & 9 & 17 & & 6 & 11 \\
\hline
\end{tabular}

proband-sibling pedigrees were complete; this corresponds to 3.7 probands needed to be enrolled for each sibling-pair pedigree for which DNA was banked at this interim assessment.

Sites were grouped as high- or low-volume sites by the number of probands approached; volume data were missing for 1 site. Thirteen high-volume sites had approached 26 or more potential probands, whereas 35 low-volume sites had approached 25 or fewer potential probands. Five sites reported approaching more than 50 potential probands; 4 sites reported fewer than 5. Eleven sites encountered more than 10 potential probands who declined to participate; 3 sites reported no such encounters. When the survey began, 3 sites had enrolled more than 25 probands; 1 site had yet to enroll any.

\section{Attitudes}

Because no statistically significant differences were found between investigators and coordinators, responses are reported for the 2 groups together. In regard to the attitudes of probands, most researchers who responded (61\%) agreed that 'probands were enthusiastic regarding participation in SWISS'; only 11\% disagreed (fig. 1A). The perception of proband concern about genetic testing in research was equally divided $(30 \%$ of researchers agreed that probands were concerned, $31 \%$ were neutral, and 38\% disagreed) (fig. 1B). Similar numbers of respondents agreed or disagreed that "probands felt that proband-initiated contact letters were important to protect their siblings' privacy' ( 23 vs. $25 \%$ ); half the respondents $(50 \%)$ were neutral (fig. 1C). More respondents agreed (31\%) than disagreed $(22 \%)$ that 'probands felt that proband-initiated contact letters were overly burdensome'; a substantial minority (45\%) were neutral (fig. 1D). 
Researchers' agreement with the following statements:

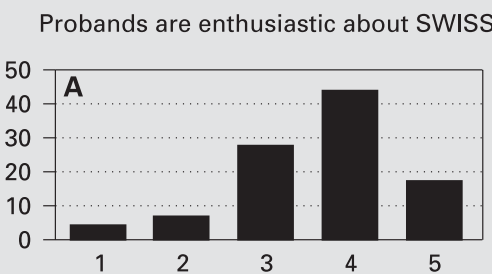

Probands feel proband-initiated contact is important to protect their siblings'

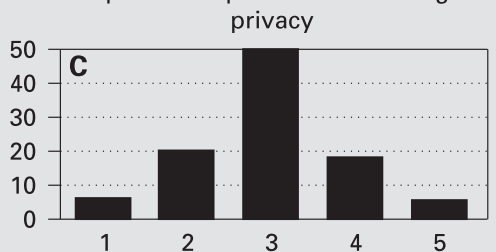

As an investigator, I feel that probandinitiated contact letters are important to protect the privacy of siblings

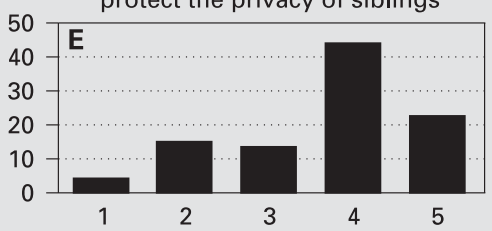

Probands are concerned about genetic testing in research

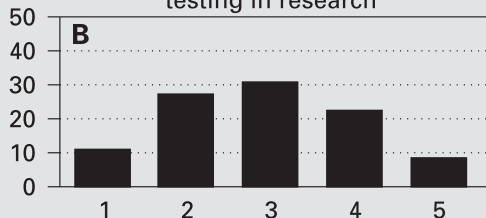

Probands feel proband-initiated contact is overly burdensome

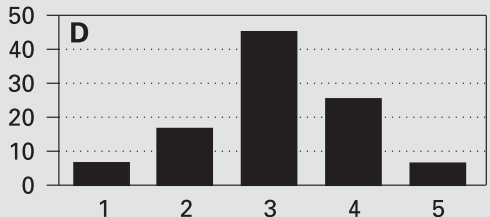

As an investigator, I feel that probandinitiated contact letters are overly

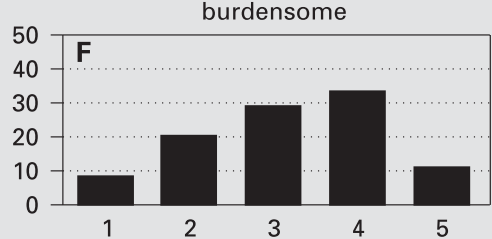

Fig. 1. Researchers (investigators and coordinators) responded to the statement across the top of each graph on a 5-point Likert scale. A-F Responses from left to right are 'strongly disagree', 'disagree', 'neutral', 'agree', and 'strongly agree'. G Responses from left to right are 'greatly impeded', 'somewhat impeded', 'no effect', 'somewhat facilitated', and 'greatly facilitated'.
Researchers' response to following statement:

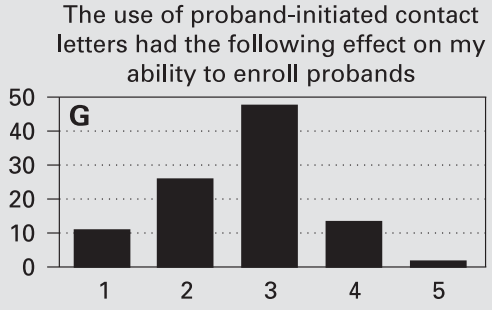

Regarding their own attitudes about proband-initiated contact, $66 \%$ of the researchers said that proband-initiated contact was important to protect the privacy of the siblings of probands, although $44 \%$ found it overly burdensome (fig. 1E and F). Of those deeming proband-initiated contact overly burdensome, 49\% (19/39) still thought it important to protecting sibling privacy. Nearly $50 \%$ of respondents thought that proband-initiated contact had neither a negative nor a positive effect on the ability to enroll (fig. 1G). Although 37\% of respondents said that proband-initiated contact impeded enrollment, $14 \%$ said it facilitated enrollment.
The attitudes of researchers about the importance of proband-initiated contact differed from their perceptions of the attitudes of the probands. Researchers rated their own sense of the importance of proband-initiated contact higher than they rated the probands' sense of its importance: $66 \%$ agreed that proband-initiated contact was important, whereas $23 \%$ agreed that probands viewed proband-initiated contact as important ( $p<$ 0.0001). Similarly, researchers tended to rate their own sense of the burden of proband-initiated contact (44\%) higher than they rated the probands' sense of this burden $(31 \%)$, but this finding did not reach statistical significance $(p=0.1)$. 
The exploratory analysis of researcher experience and site volume revealed few differences in attitudes about proband-initiated contact. We did observe that researchers who were more familiar with genetic research were less likely to perceive the proband-initiated contact as being burdensome: $31 \%$ of them disagreed with the statement that 'probands felt that proband-initiated contact letters were overly burdensome' compared with $17 \%$ of the researchers without such experience $(p=0.02)$. No significant differences in researcher attitudes were found between high- and low-volume sites.

\section{Experience with Local Research Ethics Committee Review}

Experiences with institutional review board (IRB) or local research ethics committee review of the SWISS protocol and consent forms differed widely across sites, but no IRB rejected the study for protocol concerns. Although a template consent form approved by the IRB at the overall PI's site was provided, most sites had to alter the template consent form ( 6 of 49 made major changes; 37 of 49 made minor changes). Three sites did not use the template, and 3 obtained approval without modification. Twenty sites had to submit their consent form only once to their IRB, whereas 29 sites made multiple submissions to get the consent form approved. Fourteen sites enrolling for more than 1 year had to revise their consent form at the annual renewal.

\section{Discussion}

Researchers play a key role in maintaining ethical standards in research. However, they are not routinely asked about their attitudes toward the procedures designed to protect human subjects. Nonetheless, assessing the perceptions and experiences of investigators is important for ongoing efforts to improve human subject protection strategies in SWISS or future pedigree studies. The response to this survey was robust. Data were successfully captured from every site and from nearly every researcher. Overall, the SWISS researchers perceived enthusiasm among potential probands they had approached to participate in the study.

Genetic research often relies on pedigree-based research designs [4]. Strategies to enhance the ethical standards of such research continually evolve and should be studied $[11,12]$. We found that research team members in SWISS value proband-initiated contact as a way to protect the privacy of siblings, but also perceive it as bur- densome to the proband. Interestingly, however, they do not believe that probands view proband-initiated contact to be as important a privacy protection for siblings as they themselves view it, nor do they believe that probands find proband-initiated contact as burdensome as it is to the researchers. Nonetheless, the letter-based proband-initiated contact was perceived by SWISS researchers as important both to the probands and to the researchers themselves.

At this interim assessment, nearly 4 probands were needed to enroll 1 sibling pair, a higher ratio than anticipated by the investigators on the basis of feasibility studies using a different recruitment strategy $[10,13]$. Foreknowledge of the number of probands needed to enroll (PNE) can facilitate the comparison of various recruitment methods. Just as knowing the number needed to treat can assist in the allocation of health care resources, knowing the PNE may be helpful in the planning of clinical and genetic research [10].

A substantial minority of respondents (37\%) thought that this recruitment strategy greatly impeded the conduct of the trial. The letter-based proband-initiated contact implemented in SWISS most likely does contribute to the proband-pedigree gap in enrollment. In this regard, it would be interesting to know what probands think about the use of proband-initiated contact, especially because some probands are not able to complete participation by providing a blood sample for DNA banking due to the fact that a concordant sibling has not responded.

Letter-based proband-initiated contact for study recruitment was designed to allow siblings to learn about SWISS through written material. Thus, it does not obligate the proband to know which siblings do or do not allow further contact, it allows siblings to designate whether researchers may or may not contact them further, and it allows siblings to provide contact information to the researchers. Because the researchers do not know who the affected siblings are, nonresponders cannot be reminded without further involvement of the proband to send a second set of invitation letters to all siblings.

Letter-based proband-initiated contact contrasts greatly with 'cold contact', in which researchers contact family members directly. Direct unannounced contact has been challenged even in follow-up phases of longitudinal studies [14]. Although recruitment of family members into some pedigree research has been conducted by obtaining permission and contact information from the proband $[13,15]$, this method could be viewed by family members as akin to cold contact. With increased attention to privacy concerns, privacy advocates and oth- 
ers concerned about third-party risks have challenged methods such as cold contact as invasive and unwarranted. Whether families would accept permission for contact given by probands remains uncertain but can be studied empirically.

In SWISS, family units do not complete enrollment unless at least 1 affected sibling responds. In our letterbased proband-initiated method of contact, the task of recontacting siblings when no affected siblings reply reverts to the proband. Although this approach may achieve its intended ethical objective of protecting the privacy of siblings, it also may impose an unnecessary burden on the proband. An alternative process already in use in other studies would be for probands to obtain oral permission from siblings to give their contact information to researchers [16]. This method shifts some of the responsibility for establishing sibling contact to the research team, which may result in more rapid attainment of the proband-sibling pair. It also may decrease the number of PNE, given that telephone contact usually has a higher response rate than mail contact [17]. If oral-permission proband-initiated contact proves acceptable for safeguarding sibling privacy during pedigree recruitment, then the added resources and proband burden that accompany letter-based proband-initiated contact may not be justified. Assessing actual perceptions of probands and their siblings about various recruitment methods and their pros and cons could point to areas for improvement. Studies have shown that views of research participants and potential participants do not necessarily coincide with those of researchers or research ethics policy makers $[18,19]$.

The large number of IRBs that required modification to a consent form already approved by an IRB underscores that such review remains local. This finding is consistent with experiences in other multisite studies [2022]. One-third of sites had to revise their consent forms at the annual review, suggesting that the process of IRB review for genetic observational research may be evolving at many institutions.

Our study has several limitations. As an anonymous survey, we were not able to follow up with respondents to clarify ambiguous or general responses. Although we surveyed members of the research team about their perceptions of proband perceptions and experiences, we do not have information from participants and potential participants about their own perceptions and experiences. Finally, in calculating the PNE for this interim assessment, we did not allow for the inherent lag time from proband enrollment to pedigree DNA ascertainment.
However, a formal analysis of this process has recently been completed [10].

Many authors have called for more evidence-based research ethics policies [12]. Just as with other health services, direct comparison studies - even randomized controlled trials - of recruitment strategies could enhance the ability of the scientific community to ensure scientific rigor and the appropriate protection of human subjects without instituting unnecessarily burdensome processes. In the meantime, full descriptions and evaluations of such strategies will continue to enhance the ethics and process of pedigree-based genetic research.

\section{Acknowledgments}

This study was supported by research grant R01 NS39987 from the National Institute of Neurological Disorders and Stroke.

Drs Worrall and Chen contributed equally to the preparation of the manuscript. The authors thank the investigators and coordinators of the SWISS for their participation in this survey, members of the SWISS Operations Committee for their assistance developing the survey tool, and Ray Phelps-Bowman, RN, for his critical review and advice during the preparation of the manuscript.

\section{Appendix 1}

Executive Committee: James F. Meschia, MD (chair), Mayo Clinic, Jacksonville, Fla.; Thomas G. Brott, MD; Robert D. Brown, Jr, MD; John Hardy, PhD; Brett M. Kissela, MD; Stephen S. Rich, $\mathrm{PhD}$.

Stroke Verification Committee: James F. Meschia, MD (chair), Mayo Clinic, Jacksonville, Fla.; Thomas G. Brott, MD; Marc Lojacono, CCRP; M. Jane Miller, CCRP.

Genetics Laboratory: Laboratory of Neurogenetics, National Institute on Aging, National Institutes of Health, Bethesda, Md.; John Hardy, PhD (director); Stephen Hague, PhD.

Statistical Center: Wake Forest University School of Medicine, Winston-Salem, N.C.; Stephen S. Rich, PhD (director); William Mark Brown, MD.

Clinical Coordinating Center: Mayo Alliance for Clinical Trials, Rochester, Minn.; Stephen L. Kopecky, MD (medical director); Tammy S. Olson, CTA; Kristin Simonson, RN, CTC; Roxane R. McLaughlin, RN, CTC; Raymond W. Phelps-Bowman, RN, CTC; Susan K. Quella, BSN, OCN, CTC; Karen Johnson, BA, MT (director, regulatory affairs); Virginia $\mathrm{M}$. Bruce, BS (legal contract administrator); Patricia L. Mikesh, BS (operations coordinator, data manager); Joy Frestedt, PhD (operations manager); Jagjit Gill, PhD (director, data management); Diana M. Rademacher, BS (director, data management); Barry R. Bisbee, BA (data management specialist); Nanette N. Bateman (data management assistant).

DNA Bank: Coriell Cell Repositories, Camden, N.J.; Jeanne C. Beck, PhD (director).

Phlebotomy Service: Hooper Holmes, Inc, Healthdex Division, Breaking Ridge, N.J. 
Project Officer: Katrina Gwinn-Hardy, MD, National Institute of Neurological Disorders and Stroke, National Institutes of Health, Bethesda, Md.

SWISS Participating Centers as of July 1, 2004

1 Probands enrolled: 47. Mayo Clinic, Rochester, Minn. Principal investigator: Robert D. Brown, Jr, MD. Subinvestigators: George Petty, MD; Eelco Wijdicks, MD; Irene Meissner, MD; Bruce Evans, MD; Kelly Flemming, MD; Edward Manno, MD; Jimmy Fulgham, MD; David Wiebers, MD. Coordinator: Colleen Albers, RN.

2 Probands enrolled: 37. University of Florida/Shands Jacksonville, Jacksonville, Fla. Principal investigator: Scott L. Silliman, MD. Coordinators: Barbara Quinn, RN; Cicely Bryant.

3 Probands enrolled: 33. Mayo Clinic, Jacksonville, Fla. Principal investigator: Thomas G. Brott, MD. Subinvestigators: James F. Meschia, MD; Frank Rubino, MD; Benjamin Eidelman, MD. Coordinator: Jacob Rosenberg, CRC.

4 Probands enrolled: 31 . Mercy Ruan Neurology Clinic and Clinical Research Center, Des Moines, Iowa. Principal investigator: Michael Jacoby, MD. Subinvestigators: Bruce Hughes, MD; Randall Hamilton, MD; Paul Babikian, MD; Mark Puricelli, DO. Coordinator: Judi Greene, RN.

5 Probands enrolled: 29. University of Cincinnati, Cincinnati, Ohio. Principal investigator: Brett M. Kissela, MD. Subinvestigators: Joseph Broderick, MD; Daniel Woo, MD; Daniel Kanter, MD; Dawn Kleindorfer, MD, Alexander Schneider, MD; Matthew Flahery, MD. Coordinator: Kathleen Alwell, RN.

6 Probands enrolled: 29. University of Virginia, Charlottesville, Va. Principal investigator: Bradford B. Worrall, MD, MSc. Subinvestigators: E. Clarke Haley, Jr, MD; Karen Johnston, MD, MSc; Jaclyn van Wingerden, BBA. Coordinator: Martha Davis, RN.

7 Probands enrolled: 20. Neurological Associates, Inc, Richmond, Va. Principal investigator: Francis E. McGee, Jr, MD. Subinvestigators: Stephen Thurston, MD; Thomas Smith, MD; Robert White, MD; Philip Davenport, MD; John Brush, MD; Susanna Mathe, MD; Robert Cohen, MD; J. Kim Harris, MD; John O'Bannon III, MD; John Blevins, MD. Coordinators: Sharon McQueen-Goss, RN; Janet McGee, REPT, CCRC.

8 Probands enrolled: 15. Mercy General Hospital, Sacramento, Calif. Principal investigator: Paul T. Akins, MD, PhD. Coordinator: Deidre Wentworth, RN.

9 Probands enrolled: 13. Maine Line Health-Stroke Program, Bryn Mawr, Pa. Principal investigator: Gary H. Friday, MD, MPH. Coordinator: Angela Whittington-Smith, RN.

10 Probands enrolled: 12. Centre Hospitalier Affilié Universitaire de Québec, Quebec City, PQ, Canada. Principal investigator: Denis Simard, MD. Subinvestigator: Ariane Mackey, MD. Coordinators: Annette Hache, RN; Sophie Dube, RN.

11 Probands enrolled: 11. Luther Midelfort Clinic, Eau Claire, Wisc. Principal investigator: Felix Chukwudelunzu, MD. Subinvestigators: James Bounds, MD; Rae Hanson, MD; David Nye, MD; Donn Dexter, MD. Coordinators: Tonya Kunz, RN; Karen Snobl, RN.

12 Probands enrolled: 11. Maine Medical Center, Portland, Me. Principal investigator: John R. Belden, MD. Subinvestigator: Paul Muscat, MD. Coordinator: Diane Diconzo-Fanning, RN.
13 Probands enrolled: 11. Wake Forest University School of Medicine, Winston-Salem, N.C. Principal investigator: David Lefkowitz, MD. Subinvestigators: Charles Tegeler IV, MD; Patrick Reynolds, MD. Coordinators: Jean Satterfield, RN; Elizabeth Westerberg, CCRC.

14 Probands enrolled: 10. University of South Alabama, Mobile, Ala. Principal investigator: Richard Zweifler, MD. Subinvestigators: Ivan Lopez, MD; M. Asim Mahmood, MD. Coordinators: Robin Yunker, RNC, MSN; Mel Parnell, RN, BSN.

15 Probands enrolled: 9. Cleveland Clinic Florida, Weston, Fla. Principal investigator: Virgilio Salanga, MD. Subinvestigators: Eduardo Locatelli, MD; Nestor Galvez-Jimenez, MD, FACP; Efrain Salgado, MD. Coordinators: Anupama Podichetty, MD; Jose Alvarez, MD.

16 Probands enrolled: 9. University of Pennsylvania Medical Center, Philadelphia, Pa. Principal investigator: Scott E. Kasner, MD. Subinvestigators: David S. Liebeskind, MD; Brett L. Cucchiara, MD; Michael L. McGarvey, MD; Steven R. Messe, MD; Robert A. Taylor, MD. Coordinator: Jessica Clarke, RN.

17 Probands enrolled: 8. Washington University School of Medicine, St. Louis, Mo. Principal investigator: Jin-Moo Lee, MD, PhD. Subinvestigator: Abdullah Nassief, MD. Coordinator: Denise Shearrer, RMA, BS.

18 Probands enrolled: 8. Hospital Charles LeMoyne, Greenfield Park, PQ, Canada. Principal investigator: Leo Berger, MD. Coordinators: Martine Maineville; Denise Racicot.

19 Probands enrolled: 7. Emory University School of Medicine, Atlanta, Ga. Principal investigator: Barney J. Stern, MD. Subinvestigators: Michael Frankel, MD; Marc Chimowitz, MD; Owen Samuels, MD. Coordinator: Betty Jo Shipp, RN.

20 Probands enrolled: 7. Mayo Clinic, Scottsdale, Ariz. Principal investigator: David W. Dodick, MD. Subinvestigator: Bart Demaerschalk, MD. Coordinators: Erica Boyd, RN; Rebecca Rush, RN; Gail LeBrun, RN; Nadine Lendzion, RN; Barbara Cleary, RN.

21 Probands enrolled: 7. University of California Davis School of Medicine, Sacramento, Calif. Principal investigator: Piero Verro, MD. Coordinator: Shari Nichols.

22 Probands enrolled: 7. University of Iowa Hospital, Iowa City, Iowa. Principal investigator: Patricia Davis, MD. Subinvestigator: Harold P. Adams, Jr, MD. Coordinator: Jeri Sieren, RN.

23 Probands enrolled: 7. University of Texas Southwestern Medical Center at Dallas, Dallas, Tex. Principal investigator: D. Hal Unwin, MD. Subinvestigators: Dion Graybeal, MD; Mark Johnson, MD; Mounzer Kassab, MD. Coordinator: J. Greggory Wright, BS

24 Probands enrolled: 7. University of Wisconsin, Madison, Wisc. Principal investigator: Robert Dempsey, MD. Subinvestigators: George Newman, MD; Douglas Dulli, MD; Madeleine Geraghty, MD. Coordinator: Pam Winne.

25 Probands enrolled: 7. MetroHealth Medical Center, Cleveland, Ohio. Principal investigator: Joseph P. Hanna, MD. Subinvestigators: Marc Winkelman, MD; Nimish Thakore, MD, DM. Coordinators: Alice Liskay, RN; Joan Kappler, RN; Dana Simcox, RN.

26 Probands enrolled: 7. Kaleida Stroke Center-Millard Fillmore Hospital, Buffalo, N.Y. Principal investigator: F. E. Munschauer, MD. Subinvestigator: Peterkin Lee-Kwen, MD. Coordinator: Kathleen Wrest, MLS. 
27 Probands enrolled: 7. Stroke Prevention and Atherosclerosis Research Centre (SPARC), Roberts Research Institute, London, Ont., Canada. Principal investigator: J. David Spence, MD. Subinvestigator: Claudio Munoz, MD. Coordinator: Rose Freitas.

28 Probands enrolled: 6. East Bay Region Associates in Neurology, Berkeley, Calif. Principal investigator: Brian Richardson, MD. Coordinator: Lauren McCormick.

29 Probands enrolled: 6. Indiana University School of Medicine, Indianapolis, Ind. Principal investigator: Linda S. Williams, MD. Subinvestigators: Askiel Bruno, MD; William Jones, MD.

30 Probands enrolled: 5. Helen Hayes Hospital, West Haverstraw, N.Y. Principal investigator: Laura Lennihan, MD. Coordinator: Laura Tenteromano, RN.

31 Probands enrolled: 5. Thomas Jefferson University Hospital, Philadelphia, Pa. Principal investigator: Rodney D. Bell, MD. Subinvestigators: David G. Brock, MD; Carissa Pineda, MD. Coordinator: Lisa Bowman, MNS, CRNP, CNRN.

32 Probands enrolled: 5. Ohio State University, Columbus, Ohio. Principal investigator: Andrew P. Slivaka, Jr, MD. Subinvestigator: Yousef Mohammad, MD. Coordinator: Peggy Notestine, CCRC.

33 Probands enrolled: 5. Inova Fairfax Hospital, Falls Church, Va. Principal investigator: Paul Nyquist, MD. Coordinator: Barbara Farmer, RN, MSN.

34 Probands enrolled: 4. Florida Neurovascular Institute, Tampa, Fla. Principal investigator: Erfan A. Albakri, MD. Coordinators: Taryn Chauncey, RN; Judy Jackson; Mary Katherine Taylor, ARNP.

35 Probands enrolled: 4. Marshfield Clinic, Marshfield, Wisc. Principal investigator: Percy N. Karanjia, MD. Subinvestigator: Kenneth Madden, MD. Coordinator: Kathy Mancl, CCRC.

36 Probands enrolled: 4. University of Kentucky, Lexington, Ky. Principal investigator: L. Creed Pettigrew, MD. Subinvestigators: Stephen Ryan, MD; Anand G. Vaishnav, MD. Coordinator: Deborah Taylor, MS.

37 Probands enrolled: 4. University of Maryland, Baltimore, Md. Principal investigator: Steven J. Kittner, MD, MPH. Subinvestigator: John Cole, MD. Coordinator: Mary J. Sparks, RN, BSN.

38 Probands enrolled: 3. Field Neurosciences Institute, Saginaw, Mich. Principal investigator: Faith Abbott, MD. Subinvestigators: Malcolm Field, MD; Debasish Mridha, MD. Coordinator: Richard Herm, RN, BSN, CEN.

39 Probands enrolled: 3. Johns Hopkins Bayview Medical Center, Baltimore, Md. Principal investigator: Rafael H. Llinas, MD. Subinvestigator: Christopher Earley, MD. Coordinator: Janice Alt, RN, BSN.

40 Probands enrolled: 3. Medical University of South Carolina, Charleston, S.C. Principal investigator: Timothy D. Carter, MD.

41 Probands enrolled: 3. Royal University Hospital, Saskatoon, Saskatchewan, Canada. Principal investigator: Ali H. Rajput, MD. Subinvestigator: Alexander Rajput, MD. Coordinator: Theresa Shirley, RN.

42 Probands enrolled: 3. Rush-Presbyterian-St. Lukes Medical Center, Chicago, Ill. Principal investigator: Sean Ruland, DO. Subinvestigators: Michael Schneck, MD; Michael Sloan, MD;
Phillip Gorelick, MD, MPH. Coordinator: Karen Whited, RN.

43 Probands enrolled: 3. Scripps Clinic, LaJolla, Calif. Principal investigator: Mary A. Kalafut, MD. Coordinators: Carmen James, RN; Joy Reyes.

44 Probands enrolled: 3. University of California Los Angeles Stroke Center, Los Angeles, Calif. Principal investigator: Jeffery L. Saver, MD. Subinvestigators: Bruce Ovbiagele, MD; Scott Selco, MD; Venkatakrishna Rajajee, MD. Coordinator: Gina Paek, BA.

45 Probands enrolled: 3. University of California San Diego Stroke Center, San Diego, Calif. Principal investigator: Patrick D. Lyden, MD. Subinvestigators: Christy Jackson, MD; Thomas Hemmen, MD; Brett Meyer, MD. Coordinators: Nancy Kelly, $\mathrm{RN}$; Janet Werner, RN.

46 Probands enrolled: 3. University of Illinois at Chicago, Chicago, Ill. Principal investigator: Cathy Helgason, MD. Coordinator: Joan N. Martellotto, RN, PhD.

47 Probands enrolled: 2. Chattanooga Neurology Associates, Chattanooga, Tenn. Principal investigator: Thomas Devlin, MD, PhD. Subinvestigators: Adele Ackell, MD; Sharon Farber, MD; Ravi Chander, MD; G. Hagan Jackson, MD; Kadrie Hytham, MD; Bruce Kaplan, MD; David Rankine, MD. Coordinators: Patty Wade-Hardie, RN; Tammy Owens, RN.

48 Probands enrolled: 2. Yale University School of Medicine, New Haven, Conn. Principal investigator: Mark Gorman, MD. Coordinator: Janet Halliday, RN, BS.

49 Probands enrolled: 1. Charles R. Drew University of Medicine and Science, Los Angeles, Calif. Principal investigator: George Locke, MD. Subinvestigator: Lowell Nelson, PhD. Coordinators: Marcia Montenegro, RN; Derek Knight.

50 Probands enrolled: 1. Rhode Island Hospital, Providence, R.I. Principal investigator: Janet Wilterdink, MD. Coordinator: Carol Cirillo, RN.

51 Probands enrolled: 1. Syracuse VA Medical Center, Syracuse, N.Y. Principal investigator: Antonio Culebras, MD. Coordinator: Therese Dean, RN.

Sites $19,39,41,42,45,46,47,50,51$ are closed to enrollment. 
Appendix 2. Survey for SWISS Investigators

\begin{tabular}{lll}
\hline $\mathbf{1}$ What is your role at your SWISS site? & _ PI Coordinator _ Subinvestigator \\
\hline 2 Do you have prior experience with the following research (EXCLUDING SWISS)? & \\
A Stroke treatment trials & Yes & No \\
B Stroke prevention trials & - Yes & No \\
C Nonstroke genetics trials & - Yes & No \\
D Stroke genetics trials & - No
\end{tabular}

3 Please rate the following: (Type an ' $\mathrm{X}$ ' over corresponding number; record any comments in the last section \#8)

A PROBANDS were enthusiastic regarding participation in SWISS

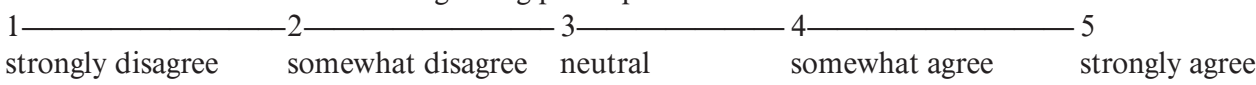

B PROBANDS were concerned about genetic testing in the context of research

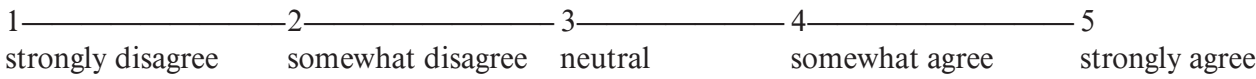

C PROBANDS felt that proband-initiated contact letters were important to protect their siblings' privacy $1-2-3-5-5$ somewhat agree $\quad$ strongly agree

D PROBANDS felt that proband-initiated contact letters were overly burdensome $1-2-3-5-5$

E As an INVESTIGATOR, I feel that proband-initiated contact letters were important to protect the privacy of siblings $1-2-3-5-5$

F As an INVESTIGATOR, I feel that proband-initiated contact letters were overly burdensome $1 \longrightarrow$ strongly disagree $\quad$ somewhat disagree $\quad$ neutral $\quad$ somewhat agree $\quad$ strongly agree

$\mathrm{G}$ The use of proband-initiated contact letters had the following effect on my ability as an INVESTIGATOR to enroll probands $1-2-3-5-5$ somewhat facilitated 5 greatly facilitated

Questions 4-7 pertain to the site experience: ONLY coordinators should answer but consult with PI as needed

4 Information about your IRB approval process:

A Characterize the changes you made to the model SWISS consent form

B Did you need to submit the consent and/or protocol more than once?

C Does your IRB allow surrogate consent for participation in SWISS?

D During your annual resubmission, were you required to make changes to your consent?

No changes
Minor changes
— Yes
Yes
Yes

$$
\begin{aligned}
& \text { Major changes } \\
& \text { _ Did not use template } \\
& \text { No } \\
& \text { _ No } \\
& \\
& \text { No }
\end{aligned}
$$

5 Approximately how many individuals has your site APPROACHED to participate?

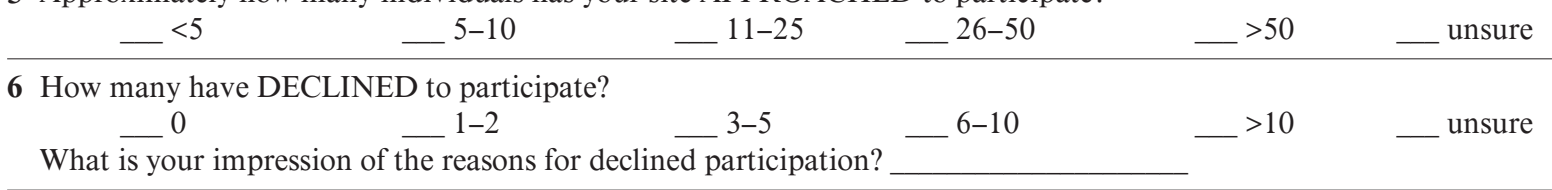

7 At your site, how many otherwise eligible patients were initially UNABLE TO GIVE CONSENT due to their stroke?

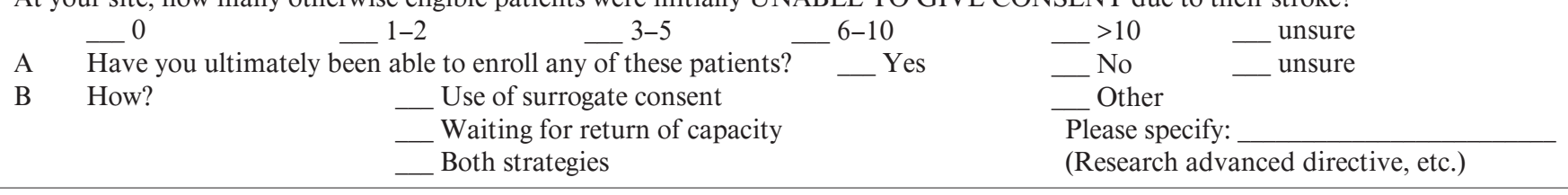

8 Do you have any comments (please use additional sheet as needed)? 


\section{References}

$>1$ Botkin J: Protecting the privacy of family members in survey and pedigree research. JAMA 2001;285:207-211.

$\checkmark 2$ Chen DT, Miller FG, Rosenstein DL: Ethical aspects of research into the etiology of autism. Ment Retard Dev Disabil Res Rev 2003;9:48_ 53.

$\checkmark 3$ Chen DT, Worrall BB, Meschia JF: Protecting the privacy of family members in research. JAMA 2001;285:1961-1963.

$\checkmark 4$ Cook-Deegan RM: Privacy, families, and human subject protections: Some lessons from pedigree research. J Contin Educ Health Prof 2001;21:224-237.

5 Worrall BB, Chen DT, Meschia JF: Ethical and methodological issues in pedigree stroke research. Stroke 2001;32:1242-1249.

6 Grady C: Ethical principles in clinical research; in Gallin JI (ed): Principles and Practice of Clinical Research. San Diego, Academic Press, 2002, pp 15-26.

7 Kahn JP, Mastroianni AC: Moving from compliance to conscience: Why we can and should improve on the ethics of clinical research. Arch Intern Med 2001;161:925-928.

$\checkmark 8$ Meschia JF, Brown RD Jr, Brott TG, Chukwudelunzu FE, Hardy J, Rich SS: The Siblings With Ischemic Stroke Study (SWISS) protocol. BMC Med Genet 2002;3:1.

-9 Adams HP Jr, Bendixen BH, Kappelle LJ, Biller J, Love BB, Gordon DL, et al: Classification of subtype of acute ischemic stroke: Definitions for use in a multicenter clinical trial. TOAST. Trial of Org 10172 in Acute Stroke Treatment. Stroke 1993;24:35-41.
10 Chen DT, Worrall BB, Brown RD Jr, Brott TG, Kissela BM, Olson TS, et al, for the SWISS Study Investigators: The impact of privacy protections on recruitment in a multicenter stroke genetics study. Neurology (in press).

11 Lavori PW, Sugarman J, Hays MT, Feussner JR: Improving informed consent in clinical trials: A duty to experiment. Control Clin Trials 1999;20:187-193.

12 Sugarman J, Eckenwiler LA, Emanuel EJ: Research oversight through new lenses: The consortium to examine clinical research ethics. IRB 2003;25:9-10.

13 Meschia JF, Brott TG, Hardy J, Brown RD Jr, Dodick DW, Cornwell KB, for the SWISS Pilot Investigators: Genome-wide screen for stroke: Pilot testing in the Siblings With Ischemic Stroke Study (SWISS). J Stroke Cerebrovasc Dis 2000:9:276-281.

14 Tyrer P, Seivewright H, Ferguson B, Johnson T: 'Cold calling' in psychiatric follow up studies: Is it justified? J Med Ethics 2003;29:238242.

15 Sutherland HJ, Lacroix J, Knight J, Andrulis IL, Boyd NF: The Cooperative Familial Registry for Breast Cancer Studies: Design and first year recruitment rates in Ontario. J Clin Epidemiol 2001;54:93-98.
16 Kaye WH, Lilenfeld LR, Berrettini WH, Strober M, Devlin B, Klump KL, et al: A search for susceptibility loci for anorexia nervosa: Methods and sample description. Biol Psychiatry 2000;47:794-803.

17 Dillman DA (ed): Mail and Internet Surveys: The Tailored Design Method, ed 2. New York, Wiley, 2000.

18 Chen DT, Rosenstein DL, Muthappan P, Hilsenback SG, Miller FG, Emanuel EJ, Wendler D: Research with stored biological samples: What do research participants want? Arch Intern Med 2005;165:652-655.

19 Wendler D, Emanuel E: The debate over research on stored biological samples: What do sources think. Arch Intern Med 2002;162: 1457-1462.

20 Silverman H, Hull SC, Sugarman J: Variability among institutional review boards' decisions within the context of a multicenter trial. Crit Care Med 2001;29:235-241.

-21 Stair TO, Reed CR, Radeos MS, Koski G, Camargo CA, the MARC Investigators: Variation in institutional review board responses to a standard protocol for a multicenter clinical trial. Acad Emerg Med 2001;8:636-641.

22 McWilliams R, Hoover-Fong J, Hamosh A, Beck S, Beaty T, Cutting G: Problematic variation in local institutional review of a multicenter genetic epidemiology study. JAMA 2003; 16:290:360-366. 